\title{
Haemodynamic and endocrinological effects of noninvasive mechanical ventilation in respiratory failure
}

\author{
J.B. Thorens*+, M. Ritz*, C. Reynard ${ }^{*}$ A. Righetti $\$$ M. Vallotton\#, H. Favre§, \\ U. Kyle ${ }^{\dagger}$, P. Jolliet*, J.C. Chevrolet*
}

\begin{abstract}
Haemodynamic and endocrinological effects of noninvasive mechanical ventilation in respiratory failure. J.B. Thorens, M. Ritz, C. Reynard, A. Righetti, M. Vallotton, H. Favre, U. Kyle, P. Jolliet, J.C. Chevrolet. (C) ERS Journals Ltd 1997.

ABSTRACT: The aim of this study was to investigate the haemodynamic and endocrinological effects of noninvasive positive pressure ventilation (NIPPV).

Eleven patients with oedema and recent hypercapnic and hypoxaemic worsening of a chronic respiratory insufficiency were included. Echocardiography, cardiac radionuclide assessment, blood catecholamines, salt and water handling hormones were measured at admission and discharge (long study (LS)). To discriminate between the action of NIPPV and other treatments, measurements were performed on the fourth day, for $4 \mathrm{~h}$ without NIPPV and $4 \mathrm{~h}$ with NIPPV (short study (SS)).

NIPPV entailed a correction of $P \mathrm{a}, C_{2}$ and an increase of $P \mathrm{a}, \mathrm{O}_{2}$ in $\mathrm{LS}$ and SS. Oedema disappeared. Body weight decreased (from $85 \pm 42$ to $81 \pm 40 \mathrm{~kg}$ ) during LS. Systolic and mean pulmonary arterial pressure decreased in LS and SS. Right ventricular ejection fraction increased in LS. Left ventricular ejection fraction did not change. Cardiac index was normal on admission and then decreased. Natriuretic peptides and catecholamines were increased on admission, whereas plasma renin activity, aldosterone and vasopressin were normal.

We suggest that in these patients, oedema can occur independently of reninangiotensin-aldosterone-vasopressin and with a normal cardiac output. Noninvasive positive pressure ventilation allowed a correction of blood gases, associated with the resolution of oedema, a decrease in pulmonary arterial pressures and an increase in right ventricular ejection fraction.

Eur Respir J 1997; 10: 2553-2559.
\end{abstract}

\begin{abstract}
* Medical Intensive Care, ${ }^{+}$Respiratory Division, \#Cardiology Center, \#Division of Endocrinology, \$Division of Nephrology, Clinical Nutrition, Hôpital Cantonal Universitaire de Genève, Switzerland.
\end{abstract}

Correspondence: J.C. Chevrolet Soins Intensifs de Médecine

Hôpital Cantonal Universitaire de Genève CH 1211 Geneva 14

Switzerland

\section{Keywords: Aldosterone} angiotensin

natriuretic peptides

noninvasive mechanical ventilation renin

vasopressin

Received: December 191995

Accepted after revision August 191997
Severe chronic respiratory insufficiency often leads to pulmonary arterial hypertension and cor pulmonale, which are associated with increased mortality [1]. Peripheral oedema is often witnessed in these patients, and the traditional view has been to assume that this results from right ventricular failure and/or the increased secretion of salt and water-handling hormone [2, 3]. Longterm noninvasive positive pressure ventilation (NIPPV) is effective in improving blood gases and thereby decreasing pulmonary hypertension, clearing oedema, and reducing morbidity and mortality associated with this condition [4]. Its beneficial effects on oedema could result from improved right ventricular function and cardiac output as well as a lowering of salt and water-handling hormone levels, as demonstrated during invasive mechanical ventilation [5]. However, there is a scarcity of published data on the consequences of NIPPV on pulmonary haemodynamics, ventricular function and hormonal patterns in oedematous patients with chronic respiratory insufficiency in which long-term ventilatory support is initiated.

The aims of this study were, therefore: 1) to measure the haemodynamic effects of NIPPV, which would be expected to reduce pulmonary arterial pressure and improve right ventricular ejection fraction because of the correction of $\mathrm{Pa}_{\mathrm{a}} \mathrm{CO}_{2}$ and $\left.\mathrm{Pa}_{2} \mathrm{O}_{2} ; 2\right)$ to explore the haemo- dynamic and endocrine profiles of patients during a recent worsening of chronic hypercapnic respiratory insufficiency, in particular the major hormones involved in the regulation of salt and water homeostasis (renin, angiotensin, aldosterone and vasopressin systems), as well as atrial natriuretic peptide (ANP) and brain natriuretic peptide (BNP). Indeed, both these peptides are elevated in proportion to pulmonary arterial pressure and atrial stretch and can enhance sodium and water excretion [6]; and 3) to measure the effects of NIPPV on the plasma levels of these hormones.

\section{Methods}

Patients were included if they presented recent worsening of chronic respiratory insufficiency, without acute respiratory failure requiring intubation, and fulfilled three of the published criteria for home mechanical ventilation [4]: morning headache, hypersomnolence, recent worsening of dyspnoea, respiratory frequency $(f R)$ of more than 30 breaths $\cdot \mathrm{min}^{-1} ; \mathrm{Pa}_{2} \mathrm{O}_{2}<8.0 \mathrm{kPa}(60 \mathrm{mmHg}), \mathrm{Pa}_{2} \mathrm{CO}_{2}$ $>6.0 \mathrm{kPa}(45 \mathrm{mmHg}), \mathrm{pH}<7.35$, breathing room air, or despite the use of long-term home oxygen therapy. Patients were equipped with an arterial line for repeated blood gas measurements. Usual treatment, including bronchodilators, antibiotic and diuretics, was instituted, as required. 
Neither steroids nor antiarrhythmics were used. Oxygen was administered either through nasal prongs or via the ventilator. Pulmonary function studies were performed in a stable state at the end of hospitalization. As our institutional Ethics Committee did not allow the insertion of a pulmonary catheter, which is not required for the routine clinical management of these patients, haemodynamic measurements were noninvasive (echocardiography and radionuclide angiography).

Exclusion criteria were: refusal to take part in the study; agitation; altered mentation or coma; and major arrhythmia or unstable haemodynamic conditions.

\section{Transthoracic echocardiography}

A tricuspid regurgitation flux (which should be present in approximately $80 \%$ of patients with pulmonary arterial hypertension) was searched for. The maximal velocity of this flux ( $\mathrm{Vmax}$ ) was measured and the systolic pulmonary arterial pressure $(P$ pa,sys $)$ was computed using the formula:

$$
P_{\text {pa,sys }}=4 \cdot \mathrm{Vmax}^{2}+P_{\mathrm{ra}}
$$

where $P$ ra is right atrial pressure, estimated for each measurement to be $10 \mathrm{mmHg}$. This method has been shown to correlate satisfactorily with measurements obtained by a pulmonary arterial catheter [7]. Using pulsed Doppler echocardiography, the time from the onset of ejection to the time of peak pulmonary artery flow velocity, termed the time to peak flow velocity $\left(t_{\mathrm{pf}}\right)$ was determined. Mean pulmonary artery pressure $(\bar{P}$ pa $)$ was then calculated by the equation: $\bar{P}_{\mathrm{pa}}=90-\left(0.62 \times t_{\mathrm{pf}}\right)$ [8]. Echocardiography was always performed by the same investigator (CR) who was blinded to the aims of the study, to allow optimal reproducibility even in obese patients in whom transthoracic echocardiography is often difficult to perform. All measurements were performed at time 1 (T1) and time 3 (T3) without NIPPV and at time 2 (T2) and time 4 (T4) during NIPPV (see Measurements protocol, below, for definition of the timing).

\section{Radionuclide assessment}

To evaluate cardiac function, a gated blood pool scanning was used. A blood sample of $5 \mathrm{~mL}$ was removed and mixed in vitro with $20-25 \mathrm{mCi}$ of Technetium-99m during $10 \mathrm{~min}$. This sample was then re-infused to the supine patient through a peripheral venous line. Images were acquired with a mobile gamma camera (Apex 215M; Elscint Corp ${ }^{\circledR}$, Israel), in the left anterior oblique (LAO) view with a craniocaudal tilt of $5-10^{\circ}$ to allow better separation between the two ventricles. The acquisition was made by a computerized system synchronized to the patients cardiac frequency. After spatial and temporal smoothing of 32 frames for each cardiac cycle, a ventricular region of interest was first automatically defined on the parametric phase image obtained by the first harmonic Fournier analysis, and then manually by drawing left and right ventricular outlines in diastole and systole. The computer then derived end-diastolic counts volume (EDV) and end-systolic counts volume (ESV). The background activity was chosen in the lateral area of the ESV frame. Ejection fraction (expressed as a percentage) was equal to the difference between EDV and ESV activities divided by EDV activity and normalized by background activity [9]. End-diastolic ventricular volumes were measured by the method of MASSARDO et al. [9]. In addition, an approximative value of cardiac output was obtained by standard equations, knowing the cardiac frequency $(f C)$ and the left ventricular ejection fraction (LVEF):

$$
\text { Cardiac output }=f \mathrm{C} \cdot \mathrm{LVEF} \cdot \mathrm{LVEDV}
$$

where LVEDV is the left ventricular end-diastolic ventricular volume.

The radionuclide assessments were performed at $\mathrm{T} 1$ and T4 only (see below), in order to avoid excessive radiation exposure.

\section{Plasma hormones}

Plasma renin activity was determined by a radioimmunoassay of angiotensin I produced after incubation of the plasma at $37^{\circ} \mathrm{C}$ for 3 hrs [10]. Plasma cortisol and aldosterone concentrations were measured by direct radioimmunoassays using commercially available kits (Diagnostic Products Corp., Los Angeles, CA, USA). Plasma arginine vasopressin concentration was measured by radioimmunoassay after extraction on octadecasilyl-silica columns (Sep-Pak C 18; Waters, Milford, MA, USA) according to LA Rochelle et al. [11]. Serum meta- and normetanephrine determinations were performed by high performance liquid chromatography followed by electrochemical detection [12].

Plasma concentrations of ANP were determined after extraction by a radioimmunoassay using the iodine- 125 $\alpha$ ANP (Amersham International, London, UK) and the antibody supplied by Peninsula Laboratories (Boston, MA, USA), as described in detail elsewhere [13]. Plasma concentrations of BNP were measured after extraction by a radioimmunoassay kit provided by Peninsula Laboratories, a method developed from KoHNo et al. [14]. All the blood hormones measurements were performed at T1, T2, T3 and T4.

\section{Bioelectrical impedance}

Bioelectrical impedance analysis (BIA) was used to determine total body water and lean and fat body masses, as described previously [15]. Briefly, an electrical current of $50 \mathrm{kHz}$ and $0.8 \mathrm{~mA}$ was produced by a generator (APIC®; Eugedia, Lyon, France) and applied to the skin using adhesive electrodes (Sentry Silver Sircuit $\AA$, SentryMedical Products, Irvine, CA, USA) placed on all right side limbs with the patients lying supine. The skin was cleaned with $70 \%$ alcohol. Resistance $(R)$ and reactance $(X)$ were used to calculate impedance $\left(Z=R^{2}+X^{2}\right)$ expressed as a function of the square of the height of the subject. Body composition was calculated following standardized equations [16]. 


\section{Nasal intermittent positive pressure ventilation}

The respirators used were the volume-cycled flow generators Kontron ABT 4100® (Milano, Italy) or Lifecare PLV-100® (Lafayette, CO, USA). The respirators were operated in assist-control mode and the settings were determined by arterial blood gas measurements. Patients were first fitted with a commercial silicone nasal mask (Respironics Inc ${ }^{\circ}$ Murrysville, PA, USA), then a silicone mask was modelled to the patient's face. Oxygen was added to the inspiratory port when necessary, to maintain arterial oxygen saturation $\left(\mathrm{Sa}_{\mathrm{a}} \mathrm{O}_{2}\right) \geq 90 \%$. At first, NIPPV was performed for 16-20 h.day ${ }^{-1}$, then the NIPPV period was gradually reduced to nocturnal use only, according to clinical tolerance and effect on arterial blood gases.

\section{Measurements protocol}

The study was divided in two phases, all the measurements being performed in the supine position. The first phase (long study (LS)) compared the data of the patients between their admission without NIPPV (T1) and discharge with NIPPV (T4) from the intensive care unit (ICU) (approximately 1 week later), the main interests of this LS being to document changes in haemodynamic and endocrine profiles before NIPPV and after patients were adapted to NIPPV.

The second phase (short study (SS)) took place 3-4 days after admission to the ICU, when the patients had mastered the technique of NIPPV. The SS compared measurements on the same day, performed when the patients had been off the ventilator for $4 \mathrm{~h}$ (T2), with those obtained after $4 \mathrm{~h}$ of NIPPV (T3). This SS was divided into two $4 \mathrm{~h}$ periods, as this duration is longer than the plasmatic half-life of the hormones assessed [17, 18]. No diuretics were administered during the short study, and for at least $4 \mathrm{~h}$ before T2. Bronchodilators, when necessary, were delivered by aerosols every $4 \mathrm{~h}$.

The SS was designed to measure the direct effect on pulmonary and systemic haemodynamics of an improvement in arterial blood gases. It allowed us to discriminate between the specific action of NIPPV (SS) and the combination of NIPPV and other treatments. No control group, consisting of patients treated with oxygen alone and standard medical treatment, was planned. Indeed it was a condition of inclusion that the patients had clear indication for ventilatory support, whether noninvasive or with endotracheal intubation. Therefore, it would have been unfeasible and unethical to provide for such a control group.

The study protocol was approved by the Ethics Research Committee of our hospital. Informed written consent was obtained from the patients or their next of kin.

\section{Statistical analysis}

All data are expressed as mean \pm standard deviation. Significance of changes in various parameters within patient group are expressed by analysis of variance (ANOVA) or by Student's paired t-test. The effects of NIPPV in LS versus SS were compared by using unpaired t-test or Wilcoxon's signed rank test when appropriate. Correlations were established by simple linear regression. A p-value of less than 0.05 was considered significant.

\section{Results}

Eleven patients were included in the study, nine of whom had peripheral oedema, while all were hypercapnic and hypoxaemic. Anthropometric and other pertinent characteristics are shown in table 1. Lung functions, measured in the pulmonary function laboratory after the patients were discharged from the ICU were: forced expiratory volume in one second (FEV1) $1.14 \pm 0.56 \mathrm{~L}$; FEV1 percentage of predicted values $42 \pm 13 \%$; forced vital capacity (FVC) $1.66 \pm 0.81 \mathrm{~L}, 48 \pm 15 \%$ pred; FEV1/ FVC $91 \pm 19 \%$; total pulmonary capacity (TPC) $4.1 \pm 1.6$ L, 74.6 $\pm 25.6 \%$ pred; and residual volume (RV) $2.3 \pm$ $1.0,118 \pm 52 \%$ pred. Diuretics were administered to seven of the patients. The mean daily dose of furosemide was $48 \mathrm{mg}$, and that of acetazolamide $120 \mathrm{mg}$.

NIPPV allowed a normalization of $P \mathrm{a}, \mathrm{CO}_{2}$ : before NIPPV (T1), $P$ a, $\mathrm{CO}_{2}$ was $7.8 \pm 1.5 \mathrm{kPa}(59 \pm 11 \mathrm{mmHg})$; at $\mathrm{T} 2$ it was $6.6 \pm 0.7 \mathrm{kPa}(50 \pm 5 \mathrm{mmHg})$; at T3, $4.8 \pm 0.7 \mathrm{kPa}$ $(36 \pm 5 \mathrm{mmHg})$; and $\mathrm{T} 4,4.8 \pm 0.5 \mathrm{kPa}(36 \pm 4 \mathrm{mmHg}) . P \mathrm{a}_{2} \mathrm{O}_{2} /$ inspiratory oxygen fraction $\left(F \mathrm{I}, \mathrm{O}_{2}\right)$ ratio improved with NIPPV (fig. 1). No scoring system was established to assess patient tolerance, but the fact that all patients could be treated successfully, as indicated by the correction in blood gases, without the need for intubation, is an indirect reflection of patient acceptability.

The haemodynamic data at the time of ICU admission and discharge are shown in table 2. Pulmonary arterial hypertension was documented in 10 patients. RVEF was decreased, while LVEF was within normal values. NIPPV did not change left ventricular function, but RVEF significantly increased, whereas RVEDV and cardiac index decreased. The effect of NIPPV on haemodynamics could be measured in the six patients who presented a tricuspid insufficiency, allowing the calculations of $\bar{P}_{\mathrm{pa}}$ and $P$ pa,sys: $\bar{P}_{\text {pa }}$ and $P$ pa,sys pulmonary artery pressures were decreased both in the SS and the LS (SS: $\bar{P}_{\text {pa }}$ before NIPPV $24 \pm 13 \mathrm{mmHg}$, after NIPPV $18 \pm 12 \mathrm{mmHg}$ ) $(\mathrm{p}<0.05), P$ pa,sys before NIPPV $52 \pm 17 \mathrm{mmHg}$, after NIPPV $43 \pm 13 \mathrm{mmHg}(\mathrm{p}<0.05)$; LS: $\bar{P}$ pa before NIPPV $34 \pm 12 \mathrm{mmHg}$, after NIPPV $21 \pm 15 \mathrm{mmHg}(\mathrm{p}<0.05)$, $P$ pa,sys before NIPPV $60 \pm 18 \mathrm{mmHg}$, after NIPPV $48 \pm$ $21 \mathrm{mmHg}(\mathrm{p}<0.05)$. Expressed as a percentage of the value before NIPPV, the decrease in $P$ pa,sys was larger in LS than in SS $(25 \pm 19 \%$ versus $13 \pm 12 \%)$, but this difference was not significant. Cardiac frequency decreased during both SS and LS: in SS, $f C$ decreased $\left(87 \pm 15\right.$ beats $\cdot \mathrm{min}^{-1}$ before NIPPV, $73 \pm 17$ beats $\cdot \mathrm{min}^{-1}$ after NIPPV; $\mathrm{p}=0.006)$; in LS, $f \mathrm{C}$ also decreased $(93 \pm 15$ beats. $\mathrm{min}^{-1}$ before NIPPV, $78 \pm 15$ beats $\cdot \mathrm{min}^{-1}$ after NIPPV; $\mathrm{p}=0.005)$. Systemic arterial pressure decreased significantly only in SS $(127 \pm 26 \mathrm{mmHg}$ before NIPPV, $118 \pm$ $20 \mathrm{mmHg}$ after NIPPV; $\mathrm{p}=0.04$ ), whereas the decrease was not significant in LS $(139 \pm 19 \mathrm{mmHg}$ before NIPPV, $123 \pm 18 \mathrm{mmHg}$ after NIPPV; $p=0.2$ ).

There was a significant correlation between the admission measurements of $P$ pa,sys and $P$ a, $C_{2}(\mathrm{r}=0.81 ; \mathrm{p}=0.05)$.

Seven patients received a mean dose of $48 \mathrm{mg}$ of furosemide (during the entire stay) and eight patients a mean dose of $118 \mathrm{mg}$ of acetazolamide (during the same period of time).

Hormonal values, in both LS and SS, are shown in table 3. The plasma levels of natriuretic peptides (ANP, BNP) and serum metanephrines or normetanephrines 


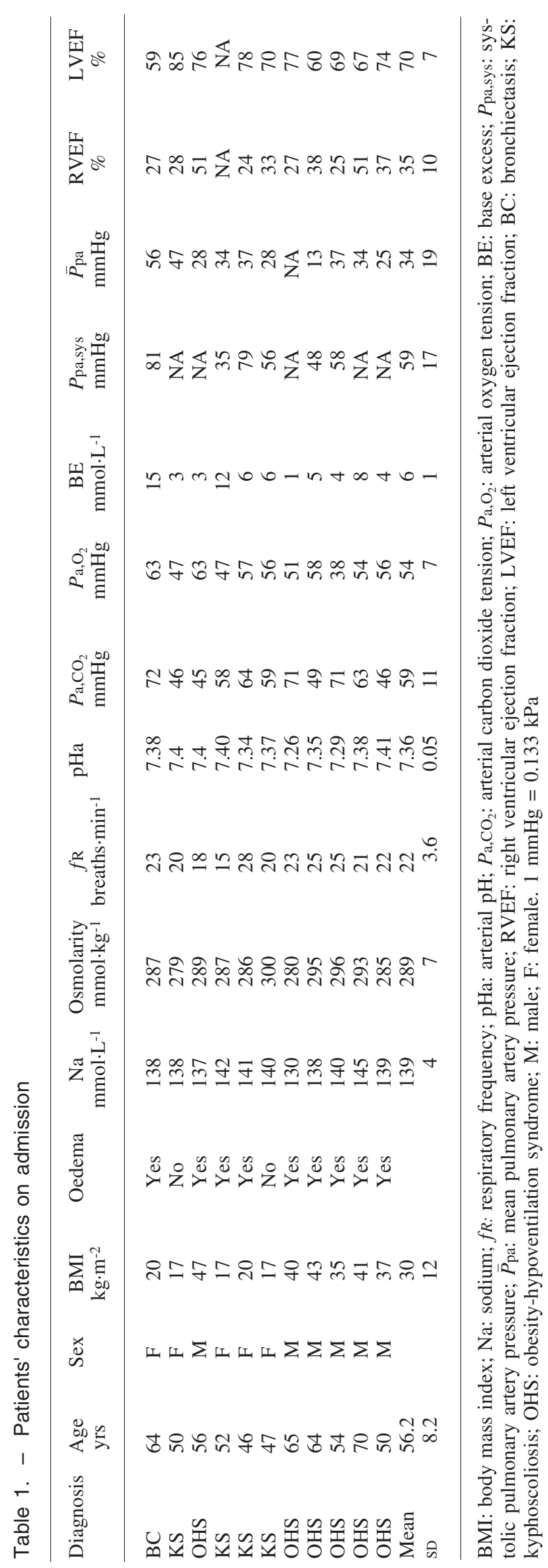

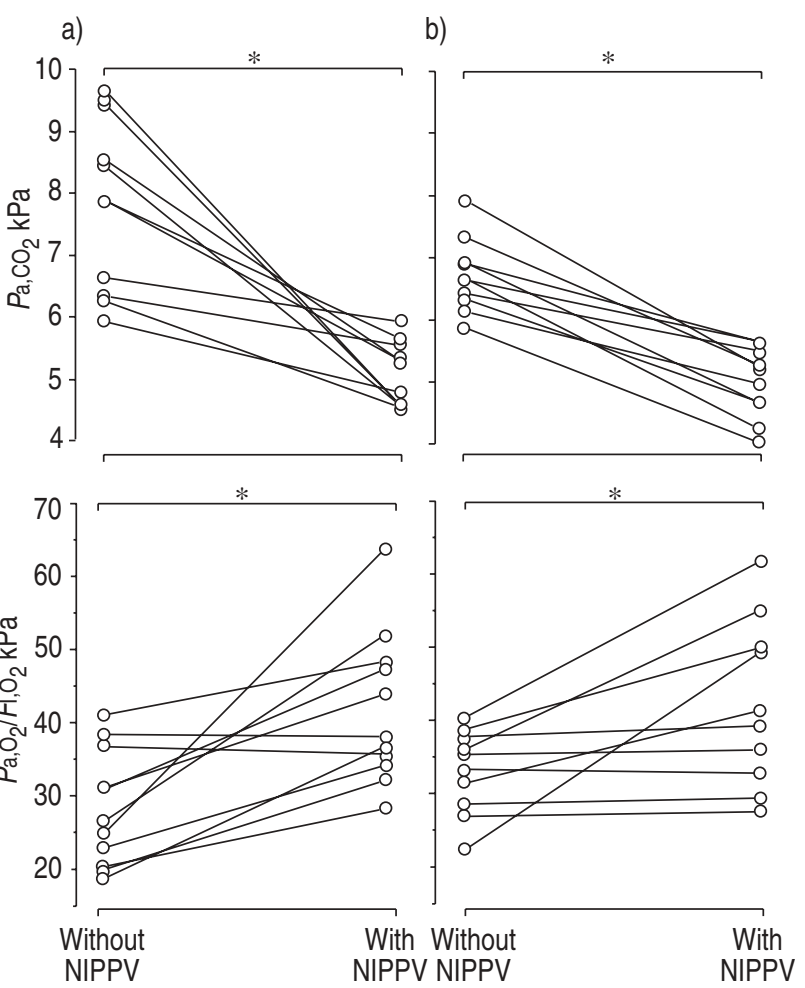

Fig. 1. - Improvement in arterial carbon dioxide tension $\left(P_{\mathrm{a}}, \mathrm{CO}_{2}\right)$ and arterial oxygen tension $\left(\mathrm{Pa}_{\mathrm{a}} \mathrm{O}_{2}\right)$ /inspiratory oxygen fraction $\left(\mathrm{F}_{\mathrm{I}} \mathrm{O}_{2}\right)$ entailed by nasal intermittent positive airway pressure (NIPPV) in: a) the long study; and b) the short study. Long study: comparison between admission and discharge from the intensive care unit. Short study: comparison between measurements made after $4 \mathrm{~h}$ without NIPPV and after $4 \mathrm{~h}$ with NIPPV. $*$ : $\mathrm{p}<0.05 .1 \mathrm{kPa}=7.52 \mathrm{mmHg}$.

Table 2. - Haemodynamics and body composition at admission to and discharge from the intensive care unit (ICU)

\begin{tabular}{lccl}
\hline & $\begin{array}{c}\text { ICU } \\
\text { admission } \\
\text { (without NIPPV) }\end{array}$ & $\begin{array}{c}\text { ICU } \\
\text { discharge } \\
\text { (with NIPPV) }\end{array}$ & p-value \\
\hline$f$ C beats·min ${ }^{-1}$ & $93 \pm 12$ & $78 \pm 15$ & 0.005 \\
RVEF \% & $35 \pm 10$ & $43 \pm 14$ & 0.009 \\
LVEF \% & $70 \pm 7$ & $70 \pm 9$ & 0.9 \\
RVEDV mL & $199 \pm 87$ & $135 \pm 55$ & 0.005 \\
LVEDV mL & $102 \pm 35$ & $93 \pm 42$ & 0.3 \\
CI L·min ${ }^{-1} \cdot \mathrm{m}^{-2}$ & $3.3 \pm 0.6$ & $2.4 \pm 0.4$ & 0.001 \\
Body weight kg & $84.9 \pm 41.7$ & $81.2 \pm 39.5$ & 0.02 \\
Total body water L & $43.9 \pm 16.2$ & $42.4 \pm 16.3$ & 0.06 \\
Lean body mass & $15 \pm 8$ & $14 \pm 8$ & 0.17 \\
$\%$ body weight & & & \\
\hline
\end{tabular}

Values are presented as mean \pm SD. NIPPV: noninvasive positive pressure ventilation; $f \mathrm{C}$ : cardiac frequency; $\mathrm{RVEF}$ : right ventricular ejection fraction; LVEF: left ventricular ejection fraction; RVEDV: right ventricular end-diastolic volume; LVEDV: left ventricular end-diastolic volume; CI: cardiac index.

were clearly increased at admission, compared to normal values [12]; norepinephrine was in the upper range of normal values. There was a significant correlation between $P$ pa,sys and both ANP and BNP at T1 $(r=0.776$; $\mathrm{p}=0.06$ and $\mathrm{r}=0.823 ; \mathrm{p}=0.04$, respectively). All other basal values were normal. There was a decrease in BNP, which was significant in LS but not in SS, and a trend toward a decrease in ANP with the use of NIPPV. No other significant change in the hormonal profiles was 
Table 3. - Blood hormone levels

\begin{tabular}{|c|c|c|c|c|c|c|c|c|}
\hline \multirow[b]{2}{*}{ Hormone } & \multirow{2}{*}{\multicolumn{2}{|c|}{$\begin{array}{c}\text { Normal value [12] } \\
\text { (supine) }\end{array}$}} & \multicolumn{3}{|c|}{ Long study } & \multicolumn{3}{|c|}{ Short study } \\
\hline & & & $\begin{array}{l}\text { Without } \\
\text { NIPPV }\end{array}$ & $\begin{array}{l}\text { With } \\
\text { NIPPV }\end{array}$ & p-value & $\begin{array}{l}\text { Without } \\
\text { NIPPV }\end{array}$ & $\begin{array}{l}\text { With } \\
\text { NIPPV }\end{array}$ & $\mathrm{p}$-value \\
\hline Cortisol nM & & $441 \pm 165$ & $429 \pm 153$ & $440 \pm 178$ & NS & $368 \pm 127$ & $324 \pm 146$ & NS \\
\hline Renin $\mathrm{ng} \cdot \mathrm{mL}^{-1}$ & & $0.89 \pm 0.66$ & $0.80 \pm 0.76$ & $1.39 \pm 1.54$ & NS & $1.07 \pm 1.52$ & $1.29 \pm 1.47$ & NS \\
\hline Aldosterone $\mathrm{nM}$ & & $0.08 \pm 0.42$ & $0.33 \pm 0.2$ & $0.36 \pm 0.33$ & NS & $0.32 \pm 0.20$ & $0.26 \pm 0.15$ & NS \\
\hline \multirow[t]{2}{*}{ Vasopressin $\mathrm{pg} \cdot \mathrm{mL}^{-1}$} & M & $1.78 \pm 1.24$ & $1.66 \pm 1.13$ & $2.52 \pm 0.58$ & NS & $2.22 \pm 1.57$ & $2.3 \pm 1.35$ & NS \\
\hline & $\mathrm{F}$ & $1.15 \pm 0.7$ & $2.22 \pm 1.62$ & $2.63 \pm 2.71$ & NS & $2.37 \pm 1.23$ & $2.58 \pm 1.45$ & NS \\
\hline Epinephrine $\mathrm{nM}$ & & $0-0.5$ & $0.36 \pm 0.32$ & $0.36 \pm 0.21$ & NS & $0.42 \pm 0.35$ & $0.41 \pm 0.38$ & NS \\
\hline Norepinephrine $\mathrm{nM}$ & & $0-4$ & $3.7 \pm 2.3$ & $2.7 \pm 1.6$ & NS & $3.4 \pm 2.2$ & $2.8 \pm 1.8$ & NS \\
\hline Metanephrine nM & & $0.6 \pm 0.4$ & $12.9 \pm 4.4$ & $9.8 \pm 6.7$ & NS & $9.4 \pm 4.1$ & $9.4 \pm 5.6$ & NS \\
\hline Normetanephrine $\mathrm{nM}$ & & $6.2 \pm 2.7$ & $28.6 \pm 16.9$ & $13.7 \pm 10.2$ & 0.08 & $17.0 \pm 8.6$ & $18.1 \pm 9.3$ & NS \\
\hline ANP $\mathrm{pg} \cdot \mathrm{mL}^{-1}$ & & $38.7 \pm 16.9$ & $101.1 \pm 56.5$ & $83.9 \pm 40.3$ & 0.09 & $115.5 \pm 68.6$ & $101.9 \pm 70.3$ & NS \\
\hline $\mathrm{BNP} \mathrm{pg} \cdot \mathrm{mL}^{-1}$ & & $10.5 \pm 2.2$ & $68.7 \pm 58.3$ & $34.5 \pm 30.0$ & 0.02 & $40.6 \pm 30.6$ & $38.0 \pm 28.8$ & NS \\
\hline
\end{tabular}

Blood samples were taken while the patients were supine. NIPPV: noninvasive intermittent positive pressure ventilation; ANP: atrial natriuretic peptide; BNP: brain natriuretic peptide; M: male; F: female; ns: nonsignificant.

detected. There was a significant correlation between $P$ pa,sys and ANP and BNP at T1 (r=0.82 and 0.77; $\mathrm{p}=0.04$ and 0.05 , respectively).

Finally, as shown on table 2, the body composition study (electrical bioimpedance measurements) showed that total body water decreased and paralleled the body weight loss, whereas the lean body mass did not change.

\section{Discussion}

In this study on patients with recent worsening of chronic respiratory failure and an indication for the institution of long-term NIPPV, NIPPV and medical treatment entailed a normalization of blood gases, a lowering of pulmonary arterial pressure and a substantial improvement in right ventricular function, as well as a major decrease in total body water, despite a decrease in the cardiac index, in less than a week. The acute effect of NIPPV added an improvement in blood gases and haemodynamics. Renin, aldosterone and vasopressin remained in the normal range between admission (without NIPPV) and discharge from the ICU (with NIPPV), whereas catecholamines and their metabolites, ANP and BNP were increased at admission. ANP and BNP plasma concentration significantly decreased between admission and discharge.

The physiological characteristics of the present patients were very close to those observed in other studies on cor pulmonale, being hypoxaemic and chronically hypercapnic, and presenting right ventricular dysfunction without any apparent left ventricular disturbance, normal cardiac output, and peripheral oedema [19]. As in other published series, in chronic obstructive pulmonary disease (COPD) patients, the present patients showed a positive correlation between $\mathrm{Pa}_{\mathrm{a}} \mathrm{CO}_{2}$ and pulmonary artery pressure [20]. Their hormonal profile was characterized by an increase in the plasma concentration of the natriuretic peptides, correlated with the magnitude of hypercapnia, and an increase in metanephrine and normetanephrine. However, we did not find any alteration in the renin-angiotensin-aldosterone-vasopressin system (RAAVS), as has been reported by others [21]. We believe, as has already been mentioned by a few authors [2, 3], that there are at least two reasons why some patients have elevated value of the RAAVS, and others do not. Firstly, some patients reported in the literature were probably hypovolaemic, due to prior administration of diuretics [22]. Hence, a potent stimulus for the activation of the RAAVS was certainly operative. In COPD patients not previously treated with diuretics, ADNOT et al. [23] found the same results as we did. With one exception, no patient had received any diuretic before entering the present study. Secondly, natriuretic peptides were recently described as potent inhibitors of the RAAVS [24]: our patients had elevated plasma levels of these peptides.

There has been virtually no studies on the effect of NIPPV on haemodynamics, and certainly none on hormonal profiles and oedema. However, one author [25] showed, in a few COPD patients, that short-term (a few hours) use of NIPPV via a face mask had no haemodynamic effect up to $20 \mathrm{cmH}_{2} \mathrm{O}$ of inspiratory pressure, except when positive end-expiratory pressure (PEEP) $(5$ or $10 \mathrm{cmH}_{2} \mathrm{O}$ ) was added. In a recent textbook on mechanical ventilation [26], it was noted that NIPPV can induce a large diuresis in some patients, but no reference or data are mentioned to substantiate this claim. The consequences of invasive positive pressure mechanical ventilation, on haemodynamics has been widely studied, particularly in COPD patients. However, the majority of these studies deal with the mechanical heartlung interactions and try to explain how positive pressure can interfere with right or left ventricular function. It is very unlikely that this type of effect could be important, or even present, in NIPPV. Firstly, as mentioned above, the only published study on haemodynamics and NIPPV did not show any effects when bedside rightheart catheterization was used [25] and, secondly, in our patients, inflation pressure was usually low, and rarely exceeded $20 \mathrm{cmH}_{2} \mathrm{O}$ at the mask level. Therefore, we believe that the effects on haemodynamics that we have observed were not mediated by mechanical interactions, but were the consequences of the major alterations of arterial blood gases, particularly $\mathrm{Pa}_{\mathrm{a}} \mathrm{CO}_{2}$. The modifications observed in the long study (table 2) may have been due to other confounding factors, including diuretics and weight loss. However, this should not be the case in the short study where only the effects of NIPPV were measured, in the absence of any other change.

Because NIPPV resulted in decreased $P \mathrm{a}, \mathrm{CO}_{2}$ and increased $\mathrm{Pa}, \mathrm{O}_{2}$ increases, we hypothesize that these alterations in blood gases had several favourable consequences. 
First, pulmonary artery pressure was reduced, according to the dependency of pulmonary vasculature tone on hypoxia and, to a lesser degree, hypercapnia. This may have caused the decrease in production of the natriuretic peptides that we observed. ANP, and probably $\mathrm{BNP}$, secretions are increased in relation to the degree of right atrial stretch [6] and their plasma levels are positively correlated with the degree of hypercapnia [27]. One could argue that the decrease of the natriuretic peptides is not really a favourable issue in a situation where they should increase urinary sodium loss and induce an inhibition of the RAAVS [24, 28]. However, it was recently shown in COPD patients, that the effects of ANP may be different, according to the severity of the disease [25]. In patients with mild COPD, the ANP secretory response to variations of volume is enhanced, indicating that ANP helps to maintain an adapted renal function to volume homeostasis. When the disease becomes more severe and the patients more hypercapnic, increased secretion of ANP is sustained, but the role of this substance as a volume regulator seems to be lost [29]. It is therefore possible, but remains to be proven that by decreasing $P \mathrm{a}, \mathrm{CO}_{2}$, and perhaps by normalizing $P \mathrm{a}, \mathrm{O}_{2}$, a more normal effect of ANP could be restored.

Several authors have shown that in patients with severe COPD and hypercapnia, aldosterone and vasopressin are increased, whereas hypercapnia and oedema are correlated [21, 22]. The present patients did not show an activation of this hormonal pathway; in addition, NIPPV did not modify the activity of this system. Several considerations should be made on this point. Firstly, due to the lack of administration of diuretics, except in one of our patient before admission, our results are consistent with others, claiming that the RAAVS is only activated in diuretic-induced hypovolemia in these patients $[2,3]$. Secondly, the absence of RAAVS activation may be due to the secretion of the natriuretic peptides [30]. Finally, when arterial blood gases were normalized by NIPPV use, even if the inhibiting effects of ANP and BNP on the RAAVS had vanished, the correction of hypercapnia would have ceased stimulation of the RAAVS.

The third hormonal system that we have explored is the catecholaminergic network. Catecholamines stimulate renin release, reduce renal blood flow and glomerular filtration rate and increase sodium reabsorption. Plasma noradrenalin is used as an estimate of sympathetic activity, and is generally elevated in hypoxic and hypercapneic patients, particularly in patients with severe COPD and oedema. As expected, we observed an increase in the catecholamines and their metabolites in our patients and NIPPV tended to decrease levels of these hormones in their plasma.

Finally, a brief comparison between the SS and LS should be made. In both situations, we were able to lower $P \mathrm{a}, \mathrm{CO}_{2}$ and $\mathrm{Pa}, \mathrm{O}_{2}$ by using NIPPV. However, the decrease in pulmonary artery pressure was larger in LS than in SS. Because the alterations of arterial blood gases were of the same degree in both situations, one could suggest that, in the LS, there was a combination of effects on the pulmonary vasculature. Firstly, a rapid and relatively direct effect on pulmonary vascular tone due to blood gas normalization and, secondly, the more longstanding action of the reduction of volemia induced by diuresis and natriuresis.

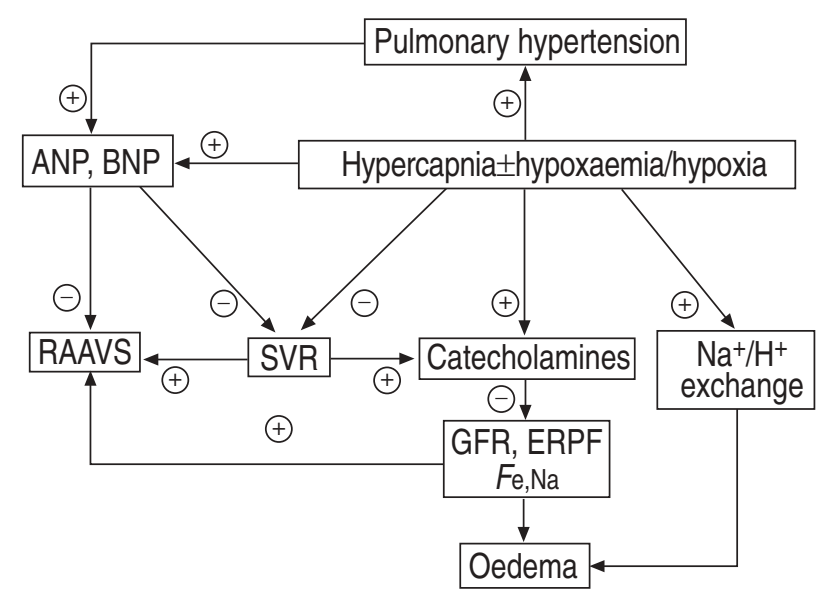

Fig. 2. - Pathophysiological hypothesis for the formation of oedema. ANP: atrial natriuretic peptide; BNP: brain natriuretic peptide; RAAVS: renin-angiotensin-aldosterone and vasopressin systems; SVR: systemic vascular resistance; GFR: glomerular filtration rate; ERPF: effective renal plasma flow; $F$ e,Na: extraction fraction of sodium; +: stimulation; - : inhibition.

Our data thus seem to provide some clues as to the reasons for success of long term home NIPPV in patients with restrictive thoracic disorders. The greatly improved prognosis of these patients is probably related in some way to the effect of NIPPV on pulmonary haemodynamics. Considering the vasodilator effect of hypercapnia and the absence of increase in the RAAVS, a tentative pathophysiological explanation for oedema formation in hypercapnic hypoxaemic patients, in the absence of a low cardiac output syndrome, is summarized in figure 2.

Our study presents four main limitations. Firstly, a control group is lacking, as oxygen therapy, diuretics and weight loss could, by themselves, result in the modifications observed in this study. However, since these patients had, in our opinion, indication for ventilatory support, constituting such a group was not feasible. Secondly, it is not possible to attribute the changes observed in the LS exclusively to NIPPV, and the other treatment modalities may have played a role as well. That is why the SS was performed. Indeed, the striking improvements of haemodynamics and blood gases observed during the SS, which are not attributable to any treatment besides NIPPV, lend support to the fact that NIPPV certainly plays a key role in the haemodynamic and blood gas changes observed in the LS (likewise, correction of hypoxaemia alone, on a short term basis, has been shown to be insufficient to reduce pulmonary artery pressure [31]). However, the LS seems highly valuable in determining the haemodynamic and endocrinological profile of these patients on admission and at discharge from the ICU. Thirdly, the small number of patients may have resulted in a type II error. For instance, some results were close to significance, such as the decrease of plasma ANP levels during the LS, or the difference in decrease of pulmonary artery pressure when comparing SS and LS. A final limitation is the nonhomogeneous nature of the study population, which included a majority of patients with restrictive pulmonary disorders, but of different causes (obesity, kyphoscoliosis), and one patient with obstructive disease. Nevertheless, the common feature was hypoxaemia and 
hypercapnia, and our efforts were aimed at its correction with NIPPV.

In summary, in a group of severely hypercapnic patients, the majority of whom were affected by a restrictive respiratory disorder and oedema, noninvasive positive pressure ventilation was well tolerated, normalized arterial blood gases, significantly improved pulmonary artery pressure and right ventricular ejection fraction, and was associated with a diuresis and a loss in total body water. Natriuretic peptides, which were elevated before the initiation of NIPPV decreased after several days of such treatment.

\section{References}

1. Massin N, Westphal J, Schrijen F, Polu J, Sadoul P. Valeur pronostique des valeurs hémodynamiques des bronchiteux chroniques. Bull Eur Physiopathol Respir 1979; 15: 821-837.

2. MacNee W. Pathophysiology of cor pulmonale in chronic obstructive pulmonary disease. Part one. Am J Respir Crit Care Med 1994; 150: 833-852.

3. MacNee W. Pathophysiology of cor pulmonale in chronic obstructive pulmonary disease. Part two. Am J Respir Crit Care Med 1994; 150: 1158-1168.

4. Hill N. Noninvasive ventilation. Does it work, for whom, and how? Am Rev Respir Dis 1993; 147: 1050-1055.

5. Scharf S. Cardiovascular effects of positive pressure ventilation. J Crit Care 1992; 7: 268-279.

6. Edwards B, Zimmerman R, Schwab T, Heublein D, Burnett J. Atrial stretch, not pressure, is the principal determinant controlling the acute release of atrial natriuretic factor. Circ Res 1988; 62: 191-195.

7. Chang K, Currie P, Seward J, Hagler D, Mair D, Tajika A. Comparison of three Doppler ultrasound methods in prediction of pulmonary artery pressure. $\mathrm{J} \mathrm{Am} \mathrm{Coll}$ Cardiol 1987; 9: 549-554.

8. Dabestani A, Mahan G, Gardin J. et al. Evaluation of pulmonary artery pressure and resistance by pulsed doppler echocardiography. Am J Coll Cardiol 1987; 59: 662-668.

9. Massardo T, Gal R, Grenier R, Schmidt D, Port S. Left ventricular volume calculation using a count-based ratio method applied to multigated radionuclide angiography. J Nucl Med 1990; 31: 450-456.

10. Vallotton M. Parallel radioimmunoassay of angiotensin I and angiotensin II for measurement of renin activity and of circulating active hormone in human plasma. In: Federlin K, Hales CN, Kracht J, eds. Hormone and Metabolic Research (Suppl. 3). Stuttgart, Thieme Verlag, 1971; pp. 94-100.

11. La Rochelle F, North W, Stern P. A new extraction of arginine vasopressin from blood: the use of octadecasilyl-silica. Pflüger Arch Eur J Physiol 1980; 387: 7981.

12. Marini M, Mathi M, Vallotton M. Dosage des métanéphrines sériques pour le diagnostic du phéochromocytome. Ann Endocrinol (Paris) 1993; 54: 337-342.

13. Oberhänsli I, Mermillod B, Favre H, Friedli B, Girardin E, Paunier L. Atrial natriuretic factor in patients with congenital heart disease: correlation with hemodynamic variable. J Am Coll Cardiol 1990; 15: 1438-1445.

14. Kohno M, Horio $\mathrm{T}$, Yokokawa $\mathrm{K}$, et al. Brain natri- uretic peptide as a cardiac hormone in essential hypertension. Am J Med 1992; 92: 29-34.

15. Segal K, Van Loan M, Fitzgerald P, Hodgdon J, Van Itallie $\mathrm{T}$. Lean body mass estimation by bioelectrical impedance analysis: a four-site cross-validation study. Am J Clin Nutr 1988; 47: 7-14.

16. Kushner R, Schoeller D. Estimation of total body water by bioelectrical impedance analysis. Am J Clin Nutr 1986; 44: 417-424.

17. Brofman J, Leff A, Munoz N, Kirchhoff C, White S. Sympathetic secretory response to hypercapnic acidosis in swine. J Appl Physiol 1990; 69(2): 710-717.

18. Rose C, Kimmel D, Godine R, Kaiser D, Carey R. Synergistic effects of acute hypoxemia and hypercapnic acidosis in conscious dogs. Circ Res 1983; 53: 202-213.

19. MacNee W, Wathen C, Flenley D, Muir A. The effects of controlled oxygen therapy on ventricular function in patients with stable and decompensated cor pulmonale. Am Rev Respir Dis 1988; 137: 1289-1295.

20. Horsfield K, Segal N, Bishop J. The pulmonary circulation in chronic bronchitis at rest and during exercise breathing air and 80\% oxygen. Clin Sci 1968; 34: 473483.

21. Farber M, Roberts L, Weinberger M, Robertson G, Fineberg N, Manfredi F. Abnormalities of sodium and $\mathrm{H}_{2} \mathrm{O}$ handling in chronic obstructive lung disease. Arch Intern Med 1982; 142: 1326-1330.

22. Anand I, Chandrashekhar Y, Ferrari R, et al. Pathogenesis of congestive state in chronic obstructive pulmonary disease. Circulation 1992; 86: 12-21.

23. Adnot S, Andrivet P, Chabrier P, et al. Plasma levels of atrial natriuretic factor, renin activity, and aldosterone in patients with chronic obstructive pulmonary disease. Am Rev Respir Dis 1990; 141: 1178-1184.

24. Anderson J, Struther A, Payne N, Slater J, Bloom S. Atrial natriuretic peptide inhibits the aldosterone response to angiotensin II in man. Clin Sci 1986; 70: 507512.

25. Ambrosino N, Nava S, Torbicki A, et al. Haemodynamic effects of pressure support and PEEP ventilation by nasal route in patients with stable chronic obstructive pulmonary disease. Thorax 1993; 48: 523-528.

26. Elliott M, Moxham J. Noninvasive mechanical ventilation by nasal or face mask. In: Principles and Practice of Mechanical Ventilation. Tobin M, ed. New York, McGraw Hill, 1994; Chapter 19, pp. 427-453.

27. Clozel J, Saunier C, Hartemann D, Alam M, Fischli W. Effects of hypoxia and hypercapnia on atrial natriuretic factor and plasma renin activity in conscious dogs. Clin Sci 1989; 76: 249-254.

28. Perreault T, Gutkowska J. Role of atrial natriuretic factor in lung physiology and pathology. Am J Respir Crit Care Med 1995; 151: 226-242.

29. Stewart A, Bardsley P, Baudouin S, et al. Changes in atrial natriuretic peptide concentrations during intravenous saline infusion in hypoxic cor pulmonale. Thorax 1991; 46: 829-834.

30. Cody R, Atlas S, Laragh J, et al. Atrial natriuretic factor in normal subjects and heart failure patients: plasma levels and renal, hormonal, and hemodynamic responses to peptide infusion. Clin Invest 1986; 78: 1362-1374.

31. Morrison D, Henry R, Goldman S. Preliminary study of the effects of low flow oxygen on oxygen delivery and right ventricular function in chronic lung disease. Am Rev Respir Dis 1986; 99: 299-305. 